\title{
A escrita didática da História na década de 1980: um ponto de reflexão para as intensas disputas públicas pelos sentidos da História ensinada no Brasil contemporâneo
}

The didactic writing of History in the 1980s: a reflection upon the intense public disputes for the meanings of History taught in the contemporary Brazil

Jean Carlos Moreno*

\section{RESUMO}

Filho dileto da modernidade europeia do século XIX, o ensino escolar de História veio se debatendo, ao menos nos últimos cem anos, com as promessas não cumpridas pelos discursos iluministas, buscando a inclusão, no campo das representações, de outras vozes e histórias dissonantes. O presente texto apresenta os desdobramentos de pesquisa de maior porte sobre os livros didáticos de história brasileiros e sua relação com o discurso identitário nacional, tomando a década de 1980 como ponto fundamental de inflexão (sem desconsiderar iniciativas anteriores importantes). ${ }^{1}$ Como exemplo, o livro Brasil Vivo, volume 1, é analisado em suas relações sincrônicas e diacrônicas com as demais produções didáticas da disciplina de História. Procura-se, ao final, partindo das análises realizadas, refletir sobre a intensa disputa pública pelos sentidos da História ensinada no Brasil contemporâneo.

Palavras-chave: ensino de História; livros didáticos; identidade nacional.

\section{Abstract}

A dear child of the 19th century European modernity, History teaching in schools has been debated, in the last hundred years at least, with the nonfulfilled promises of the Illuminists, searching for the inclusion in the representation field of other dissonant voices and histories. The current text presents the continuity of a bigger research about Brazilian History textbooks and their relation to national identity discourse, taking the 1980s as a fundamental point of inflection (not disregarding the important past initiatives). As an example, the book Brasil Vivo is analysed in its synchronic and diachronic relation to the other didactic production of the History subject to Secondary School. We aimed to reflect on the intense public dispute for the meanings of History taught in contemporary Brazil.

Keywords: History teaching; textbooks; national identity.

\footnotetext{
* Doutor em História pela Universidade Estadual Paulista "Júlio de Mesquita Filho" (Unesp). Professor Adjunto da Universidade Estadual do Norte do Paraná (UENP). Jacarezinho, PR, Brasil. jeanmoreno@uenp.edu.br
} 
A relação entre formação de identidades, ensino de História e cultura Histórica é conhecida de longa data e reforçada pelos estudos contemporâneos. Contudo, análises recentes apontam a permanência, entre pensadores brasileiros, de "um sentimento de plena integração do país ao relato padrão da ascensão do Ocidente, forjado no decorrer do século XIX, que impregna profundamente as maneiras como concebemos o passado" (Gonçalves, 2014, p.92). Essa situação torna-se ainda mais intensa num mundo e num país onde voltam a emergir discursos de viés antidemocrático e fundamentalista nos quais a diversidade e os direitos humanos são postos novamente em xeque.

É num caminho de invenção e renovação do espírito público que o ensino e a aprendizagem de História são desafiados na contemporaneidade, entendendo também, como diz Rüsen, que outra maneira de tratar a aprendizagem deve ser buscada, espelhando a autoexperiência de cada sujeito, "seus desejos, esperanças, expectativas e medos na experiência histórica da variedade das formas de vida e das várias ideias inerentes sobre a humanidade no transcurso do tempo" (Rüsen, 2015, p.35). Faz-se, cada vez mais, necessário o enfrentamento do caráter monocultural e do etnocentrismo presentes na escola e na cultura histórica, contribuindo para desestabilizar a pretensa universalidade dos conteúdos escolares e do relato hegemônico do Ocidente.

\section{ENSINO DE HistóRIA E REPRESENTAÇÕES IDENTITÁRIAS}

Há muito tempo os pesquisadores perceberam que toda narrativa histórica estabelece, por distintas formas, a identidade de seus autores e ouvintes. Referência central para os estudos contemporâneos sobre a aprendizagem histórica, Jörn Rüsen (2001, p.88) considera que “A 'identidade histórica’ é o termo comum para a consistência diacrônica dos sujeitos no curso do tempo. Essa identidade é especificamente histórica quando suas dimensões temporais ultrapassam as fronteiras de sua própria vida e a finitude dos indivíduos é superada por meio da memória”.

É forçoso perceber, contudo, que, na modernidade, a nação como "princípio de visão e di-visão" (Bourdieu, 1989) da organização política e social tornou-se elemento onipresente em discursos identitários hegemônicos. Embora não coadune sempre com os padrões de racionalidade e lógica ideados pela modernidade, o discurso da nacionalidade foi capaz de dar conta de uma 
perspectiva de futuro e de transformação e, ao mesmo tempo, eliminar, ao menos no nível simbólico ou imaginário, o caos e a desordem. A nacionalidade, portanto, como discurso histórico, é provocadora de atos mentais determinantes do comportamento, que subjazem à lida com a História (cf. Schörken, 1972, apud Rüsen et al., 2011, p.42): produção de identidade, lealdade, simpatia, subjetivação e individualização.

Contudo, a crescente complexidade das dinâmicas sociais e a aceleração das transformações tornaram mais visíveis os jogos e disputas por identidades, que são, cada vez mais, conscientemente mobilizadas no campo político no mundo contemporâneo. Para muitos analistas (Hall, 2003; Bauman, 2005; Woodward, 2009, etc.), uma das categorias sociais - antes utilizadas, quase como evidentes ou naturais, para atribuir identidades aos diferentes sujeitos - que é colocada em xeque é a nacionalidade. Diferenças, antes obscurecidas por essa macrocategorização, são, na atualidade, iluminadas tanto pelas lentes acadêmicas quanto pelas práticas sociais.

Mas a aparência de reconhecimento da diversidade contemporânea pode ser apenas uma perspectiva ilusória, quando se levam em conta somente relações de troca idílicas, sem abordar a desproporcionalidade de poder econômico e simbólico nos intercâmbios multiculturais:

A alteridade indica agora o claro desafio das culturas diferentes da hegemônica, do Oriente ao Ocidente, do islã ao cristianismo, das étnicas e locais às nacionais ... a alteridade evidencia que não pode haver uma relação profunda entre as culturas sem que ocorram conflitos em sua dinâmica. "Reconhecer" as demais culturas é impossível sem assumir o profundo vínculo da "diferença" com a desigualdade social e a discriminação política, ou seja, colocando em primeiro plano a indispensável ligação entre direitos culturais e sociais. (Martín-Barbero, 2009, p.154)

Fruto e também sujeito da modernidade, como um suporte de conteúdos e valores, meio e mensagem de uma seleção cultural, que, obrigatoriamente, tem que dialogar com um público receptor (professores, alunos, comunidade, autoridades governamentais e pedagógicas), o livro didático de História tornou-se um dos espaços privilegiados de disputa por representações identitárias, sejam de etnia, classe, gênero, nação etc. O discurso didático pode ser pensado, então, como um espaço de desdobramento dos debates intelectuais, mas que também pode conter - por que não? - apropriações diferenciadas, 
releituras e contradiscursos, especialmente em um momento no qual há um aumento da quantidade de produtos simbólicos referentes ao passado e à sua interpretação (cf. Rosa et al., 2008).

O projeto identitário brasileiro construiu representações fundadoras, reiteradas e debatidas ao longo do tempo, que idealizaram uma sociedade harmônica, especialmente com a representação da união das três raças e seu corolário, a ideia de democracia racial. Isso nos leva a observar o peso de aspectos do período colonial, destacados pela produção didática como fundadores da nação, substancialmente as representações a respeito de cada um dos elementos que compõem a representação fundadora das três raças - negros, índios e brancos ${ }^{2}$ - e as intrigas construídas em torno desses agentes. O foco dessa representação identitária está ligado ao período de colonização portuguesa, entendido como momento de "encontro" entre as diversas culturas que deram origem à sociedade brasileira contemporânea. Esse momento fundador é relido conforme a orientação política e as determinantes epistemológicas que envolvem o ensino de História em cada período.

Tal percepção guia a incursão que fizemos pelos livros didáticos de História produzidos na década de 1980. Utilizando-se da metodologia da análise de representações, buscou-se centrar atenção aos aspectos específicos do ensino escolar de História, entre os quais estão questões de linguagem, afetividade, desenvolvimento moral, cognição, horizonte de expectativas e, mais especificamente, os discursos identitários. Por entre rupturas e continuidades, vislumbram-se atividades reflexivas propondo polêmicas, debates, encenações e um maior posicionamento perante a função social da disciplina em relação às coleções didáticas predecessoras. É dessa forma que a coleção Brasil Vivo, de Chico Alencar, Marcus Venicio Ribeiro e Claudius Ceccon, compartilha com a produção do seu tempo uma forte preocupação com a reconfiguração dos discursos identitários brasileiros pela utilização de textos mais dramáticos, envolventes e emocionais.

\section{BRASIL VIVO E AS REPRESENTAÇÕES DO POVO BRASILEIRO}

Muita pressão social e negociação foram necessárias para o retorno à democracia política no Brasil no início dos anos 1980. Nesse contexto, mais do que em outras épocas ficava claro para os agentes educacionais que pensar educação 
e ensino de História implicava a formulação de um projeto político. Assim como, anteriormente, desempenhava função central de instituidor da nação, caberia agora ao ensino de História no Brasil um papel de vanguarda, senão como instituidor, ao menos como um propugnador do exercício da cidadania junto à população estudantil. Se a educação e o ensino de História estavam vinculados, de maneira explícita e veemente, nos discursos sobre a escolarização, a questões políticas e sociais do país, não menos estariam ligados às esperanças, aos projetos de superação de desigualdades e injustiças, às utopias.

Vários pesquisadores apontam um vácuo de prescrição governamental na primeira metade da década de 1980, o que levou autores e editoras a ter maior liberdade de ação na manutenção ou criação de um currículo informal, mas unificado, para o ensino de História, mesmo após a implementação dos currículos estaduais. O avistar de um "campo aberto", proporcionado pelo fim do regime autoritário, mostrava espaço para uma intervenção maior, e os agentes educacionais, incluindo autores didáticos, agiriam como sendo necessário e possível desconstruir representações que estavam assentadas no imaginário brasileiro havia muito tempo. Assim se fez com as representações da população brasileira como uma sociedade pacífica, harmônica, una e indivisa, portadora de uma democracia racial.

Com uso de recursos literários, linguagem afetiva (um texto mais "livre" que torna a narrativa mais "viva"), mobilização dos sentimentos, axiologização mais evidente dos conhecimentos históricos, rompimento explícito com a concepção da sociedade brasileira harmoniosa, o livro Brasil Vivo, que se propunha a apresentar "uma nova história da nossa gente", é um marco da produção didática de História da década de 1980.

Chico Alencar, à época da produção da obra, era professor da rede pública, presidente da Federação das Associações de Moradores do Estado do Rio de Janeiro (Famerj) e graduado em História. Marcus Venicio, graduado em Ciências Sociais, professor de escolas particulares e pesquisador da Fundação Nacional Pró-memória. Ambos já haviam publicado, com Lúcia Carpi, o livro História da Sociedade Brasileira pela editora Ao Livro Técnico. ${ }^{3}$

Alencar e Venicio convidaram para ilustrar a obra o cartunista, já reconhecido por seus trabalhos na grande imprensa e na imprensa alternativa, ${ }^{4}$ Claudius Ceccon, formado em Arquitetura, professor universitário e coordenador do projeto Vídeo Popular do Instituto de Estudos da Religião (Iser). De 
fato, as charges produzidas por Claudius são centrais para a obra, o que justifica seu nome constar como autor na capa.

A obra, lançada em 1986, trazia algumas características diferenciais, a começar pela própria editora. A Vozes já trazia em seu catálogo obras voltadas a escolas, mas seu foco não era o mercado didático. Contudo, a editora franciscana tornou-se a principal divulgadora do discurso social católico e de oposição ao regime militar nas décadas de 1970 e 1980. A vinculação de Brasil Vivo com os movimentos populares e uma nova interpretação do cristianismo católico para toda a América Latina evidencia-se não só na trajetória profissional dos autores como também em algumas passagens do livro.

Publicado em formato grande $(21 \times 27 \mathrm{~cm})$, assim como todos os demais livros didáticos do período, tinha capa e contracapa impressas em vermelho. No centro da capa um recurso gráfico que indica explosão - ou uma estrela de várias pontas. Dentro da figura, a ilustração de multidão em passeata segurando várias faixas; à frente destacam-se uma mulher, um homem do campo, um índio e um operário, numa segunda fila aparecem um homem negro e um padre. Esses personagens carregam a faixa com os dizeres: "uma nova história da nossa gente", a indicar uma perspectiva bastante diferente: não se tratava mais de uma História do Brasil, mas da gente brasileira.

O livro 1 abrange a história do Brasil até o fim do período imperial. Os títulos dos capítulos são provocativos ("O Mundo da terra de todos"; "Pai durão, mulher medrosa, filhos assustados!"; "Pau, pano e pão"; "Está nascendo um país"; "Vem chegando o rei café”; "As transações do Império"; "Caiu de madura") e as informações históricas são diluídas na narrativa. Centramos nossa análise nos três primeiros capítulos que são referentes ao período da colonização portuguesa e abordam, como tema central, índios, portugueses e negros, respectivamente.

Logo na apresentação da obra, os autores situam seu posicionamento diante do ensino de História. Inicialmente diagnostica-se aquilo que se quer superar: "a história que nós, autores, aprendemos na escola, nunca teve nada a ver com o ar, com o mar, com a vida. Era aquele amontoado chato de nomes de heróis e fatos passados, com um cheiro danado de bolor" (p.5). Se "a História é como o ar que respiramos: está sempre presente, mesmo sem a gente perceber" e se “é como o mar, sempre em movimento", é preciso que a História (contada, escrita) de um país específico contemple essa perspectiva: 
A nossa História é rica, agitada e viva. Cheia de alegrias e dores, bem do jeito das pessoas todas que aqui vivem. Movida pela força dos grupos humanos, com caras, hábitos e interesses diferentes, a História do Brasil vai sendo construída entre sons e silêncios, festas e prisões, paixões e tiroteios, carinhos e ódios. História é vida, é continuação. É o que foi, o que está sendo, o que será. Seu grande personagem somos todos nós. (p.5)

O capítulo 1, com o título "O Mundo da Terra de Todos", trata dos povos indígenas. Um recurso importante, utilizado pelos autores, que confere sentido especial à narrativa histórica, é o de nomear os personagens, mesmo as pessoas comuns. $\mathrm{O}$ "dar nome" traz à existência personagens concretos (mesmo que fictícios) e mobiliza recursos afetivos. O personagem central que abre e constrói sentido para a história indígena é Tsipré, um jovem xavante (do Mato Grosso), cujo nome quer dizer, em português, "Pássaro Vermelho". Tsipré acabara de sonhar o seu canto (rito de passagem para a vida adulta). A vida de Tsipré é a senha para a entrada em mundo indígena paradisíaco, contraponto da sociedade moderna com controle do tempo, acumulação, exploração, preocupações e sobrecarga de trabalho.

Nota-se claramente a busca da inversão do discurso. Se antes o indígena era visto como preguiçoso e alguns autores, na década de 1970, esforçavam-se para mostrar que os nativos trabalhavam duramente para conseguir seu sustento, agora o não se preocupar em trabalhar para produzir a mais do que se precisa em um dia torna-se representação positiva. ${ }^{5}$ Há nessa obra - e em muitas outras da década de 1980 - um elemento de crítica à acumulação e ao excesso de trabalho, interpretação decorrente não apenas do marxismo, mas de toda uma vivência cultural das décadas anteriores a que se costuma chamar de contracultura. Nela estão incluídos o pensamento ecológico e o retorno a uma vida simples (contrapondo-se à artificialidade do moderno) baseada na relação direta com a natureza. O principal elemento, contudo, nessa perspectiva de representação das sociedades indígenas é a comunhão dos bens materiais.

O contato entre indígenas e europeus é abordado ainda nesse capítulo a partir do subtítulo "Gente que entra sem pedir licença". A vida na Europa é comparada à situação dos indígenas na América, ou, melhor dizendo, à de Tsipré e seus irmãos. A principal diferença está no fato de que "na Europa os 
trabalhadores tinham que entregar boa parte do que produziam para um senhor todo-poderoso" (p.14).

Após breve trecho da Carta de Caminha, os autores comentam: "chegava o branco vendo os homens das diferentes nações e grupos tribais como uma coisa só: índios simplesmente" (p.17). Dominação cultural e econômica é a base da ação dos portugueses sobre os índios e o território conquistado.

A ação dos portugueses, consciente e violenta, gera a destruição das culturas indígenas. A partir daí "Tsipré, Watsi, Umakeró e Denakê tornavam-se estrangeiros... em sua própria terra!” (p.28), pois “os portugueses consideravam-se os únicos donos do Brasil. E viram logo que, para ocupá-lo, tinham que dominar seus habitantes. Para eles, estes nativos, não passavam de 'bárbaros' e 'selvagens'. Ser diferente era ser inferior" (p.28). O discurso da ausência - "não lavram, nem criam..." e "não têm fé, nem lei, nem rei" - é revertido, mostrando o estranhamento dos portugueses diante de culturas que desconheciam.

Para os autores foi assim que "começou a se fazer o Brasil. Pela violência da arma de fogo e da doença ou pela violência macia da catequese” (p.20). A crítica à ação da Igreja na colonização - que coincidia com a autocrítica feita pela própria instituição desde a Segunda Conferência Geral do Episcopado Latino-Americano, realizada em 1968 - é também uma mudança no discurso histórico e identitário brasileiro que se opera com mais ênfase na produção didática dos anos 1980. No $2^{\circ}$ capítulo, especificamente no subtítulo "Adorando a Deus e ao dinheiro", os autores ironizam a missão dos portugueses de levar a fé cristã e a civilização aos povos "atrasados".

Os autores enfatizam também a resistência indígena, apresentando, aliás, heróis e mártires. Os guerreiros manau, na Amazônia, por exemplo, "não aceitavam a invasão de suas terras, nem a escravidão de sua gente e resistiram até morrer, até o extermínio total, pois os brancos sempre foram superiores em armamentos" (p.19). Assim como Ajuricaba, líder dos manau, Sepé Tiaraju, das missões dos sete povos, também é exaltado como símbolo da resistência indígena.

Os autores dão grande destaque à situação dos grupos indígenas na atualidade. Apresentam um mapa do Brasil com uma representação gráfica, seguida da legenda: "dos 6 milhões que viviam aqui quando os portugueses chegaram... hoje restam 200 mil”. Enumeram, também, diversas nações nos 
mais variados estados brasileiros que tentam resistir ao domínio de seus territórios. Ressaltam os autores, entretanto, que "só neste nosso século desapareceram 800 mil índios de 90 nações diferentes" (p.13). Para eles, "Os invasores da floresta, hoje, têm outros nomes: Volkswagen, Swift, Nixdorf, Brascan, Jari... grandes empresas nacionais e internacionais que vão abrindo estradas, derrubando milhares de árvores por dia, levando o 'progresso', com muito gado gordo e boiadeiro magro".

Durante todo o capítulo, o texto é permeado por depoimentos de representantes indígenas. Além de reforço de comunicação, trata-se de outro postulado que permeia a produção didática de História desse período: dar voz aos sujeitos tradicionalmente oprimidos e excluídos dos projetos oficiais. "Índio não é bicho para amansar. Amansar pra poder ficar assim manso e o branco aproveitar a terra dele” (p.14), diz Awatekãto’i, chefe tapirapé.

A finalização do capítulo retoma as diferenças culturais e, mais uma vez, mostra a sociedade indígena como contraponto das sociedades modernas: "esses povos, muito diferentes de nós e também diferentes entre si, precisam aprender com os brancos?” (p.21). Nesta mesma direção de outra sociabilidade, talvez, para os autores, perdida pelo desenvolvimento urbano contemporâneo, o livro traz depoimentos de indígenas em favor do seu modo de vida.

A chegada dos portugueses, assunto do capítulo 2, inaugura o Brasil, mas também é o prelúdio de um tempo de sofrimento: "O Mundo da Terra de todos passava a ser uma colônia de exploração. A terra tinha outro dono, uma metrópole distante, forte e poderosa: Portugal" (p.28). Numa charge da página 29 um navegador observa com uma luneta e exclama: "oba! Loteamento à vista!". O caráter fundador do período colonial mais uma vez se pronuncia, mas agora com sinal invertido. Ao comentar sobre as sesmarias, os autores constatam que "nasciam assim as grandes propriedades e latifúndios que até hoje existem em nosso país" (p.31).

A intenção dos portugueses de apenas explorar as novas terras evidencia-se no juramento de um colonizador português na véspera de sua viagem ao Brasil: "juro que (no Brasil) não farei nenhum trabalho braçal, enquanto conseguir um só escravo que trabalhe para mim com a graça de Deus e do rei de Portugal” (p.29). A ganância na ação colonizadora é destacada também no relato sobre os bandeirantes. Na página 37 há uma ilustração de um 
bandeirante. No lugar de seus olhos estão pedras preciosas, e sua expressão é de extrema cobiça.

Contudo, não é esse o assunto central do capítulo 2, "Pai durão, mulher medrosa, filhos assustados!”. Há um predomínio de interpretações baseadas em Casa-grande \& senzala nesse capítulo. A apropriação de Gilberto Freyre evidencia a polissemia do autor e sua obra, que proporciona leituras comprometidas com os mais diversos espectros políticos. O capítulo versa sobre o autoritarismo - ou mandonismo - na sociedade brasileira. Inicia com a educação das crianças no período colonial, com o subtítulo "Escreveu, não leu, o pau comeu!", onde se descrevem os vários tipos de castigos em casa e na escola. A repressão sobre as crianças da elite branca é comparada à vida livre de Tsipré. Os portugueses construíram um mundo da educação pela violência em terras americanas.

O senhor de engenho é o exemplo maior desse autoritarismo. "Os senhores eram donos de tudo: terra, engenho, escravos. E mandavam em todos: nos escravos, nos índios domesticados e também nos homens livres, mas pobres, que não tinham terra nem engenho" (p.31). Pela leitura do texto infere-se que o senhor era o topo de uma cadeia de mandonismo e violência.

O papel dos padres na conformação da relação mando-submissão é reforçado com o subtítulo "quem manda na região, manda na religião". Os autores deixam claro que "os padres obedeciam mais aos senhores de engenho do que ao papa!” (p.32) e que o trabalho da Igreja facilitava o pacto colonial, pois "quem obedece ao rei agrada a Deus". Na página 32 há uma charge em tamanho grande de senhor de engenho, imponente; atrás dele há um padre coroando-o, e à sua frente pessoas prostradas, ajoelhadas, reverenciando-o. $\mathrm{O}$ senhor apoia o pé sobre uma delas.

Evidentemente, a família do período colonial não poderia diferir desse modelo autoritário. Utilizando-se da constatação de Antonil, "Quem chegou a ter título de senhor parece que em todos quer dependência de servos. Todos, até mesmo da mulher e filhos" (p.33), os autores representam a família patriarcal como composta por chefe mandão, mulher submissa e medrosa, e filhos assustados e obedientes. Contudo, registram exceções de mulheres poderosas, administrando engenhos, e aproveitam o assunto para problematizar a questão da mulher no presente. 
O terceiro capítulo, centrado na vida dos africanos que vieram para o Brasil, tem o título "Pau, pano e pão". A partir do subtítulo "no início só existia Olorum", inicia-se o capítulo com um mito de criação nagô, narrando o conflito e a reconciliação entre Obatalá e Odudua - o masculino e o feminino. Assim como se fez para os indígenas, nomeia-se e usa-se, no decorrer da narrativa, o nome de várias nações africanas de língua yorubá - Kétu, Sabe, Oyó, Ebgá... - e bantos - Cabinda, Benguela, Caçanje, Muxicongo. Reinos teocráticos e comunidades tribais são identificados dentro da diversidade de organização política do continente africano.

A existência da escravidão no continente também é comentada. Anteriormente, em alguns compêndios e livros seriados, a existência da escravidão na África era justificativa ou forma de legitimação moral da existência da escravidão no Brasil. Provavelmente cientes desse tipo de argumentação, os autores tentam distinguir a escravidão africana da escravidão comercial empreendida a partir do século XVI.

Caçados na Guiné, em Angola e no Sudão, africanos escravizados viajavam nos terríveis navios negreiros. O terror dos castigos para aqueles que se rebelavam nos navios é enfatizado. Chegando ao Brasil, não são mais gente, mas sim coisa, mercadoria. ${ }^{6}$ No subtítulo "Trabalho é 'coisa de negro", o texto se inicia com uma série de perguntas semelhantes àquelas do poema "Quem Construiu a Tebas de Sete Portas? (Perguntas de um Trabalhador que lê)”. No lugar do trabalhador de Brecht, estaria o negro escravizado. Conclui-se que "sem escravo não tinha açúcar, não tinha ouro, não tinha diamantes... Não tinha casa-grande, nem tinha senhor!” (p.48). O texto é permeado por muitas imagens de Debret.

Essa parte do capítulo é dedicada também à permanência da mentalidade escravista, pois se espalhara "nas colônias um mundo de ideias que faziam a escravidão parecer a coisa mais natural do planeta" (p.50), a partir de uma "suposta superioridade dos europeus" (p.50). Como consequência, além da desvalorização do trabalho pela sociedade brasileira, após a abolição, o negro “continuou sendo visto como inferior, uma 'sub-raça'...” (p.50).

A questão do conformismo disseminado pela religião é posta mais uma vez em destaque a partir da fala do padre Antônio Vieira: "a escravidão do negro é um meio de sua salvação, uma entrada no Reino de Deus. A salvação está na cruz. Servindo ao seu senhor aqui na terra, o cativo receberá o prêmio 
no céu" (p.55). Adiante, novamente os castigos cruéis são ressaltados, inclusive com "senhoras enraivecidas quebrando com chutes os dentes das escravas por ciúmes dos maridos" (p.53). Aliás, a questão da mulher escrava também é abordada pelos autores: "Para as mucamas, cair no agrado do senhor podia representar também a proteção contra muitos castigos. E até a alforria. Deixavam de ser escravas para o trabalho, mas continuavam escravas dos desejos dos seus patrões" (p.55).

Contudo, os autores destacam que "onde há opressão, há resistência. Os negros resistiam, lutavam muito. Onde havia negros trabalhando, lá explodia a revolta!" (p.58). Para "reencontrar a harmonia perdida, a guerrilha contra os dominadores brancos era inevitável” (p.58). Os autores, então, comentam e nomeiam quilombos existentes em várias províncias do país. Nomeiam-se também as lideranças de Palmares - Ganga-Zumba, Pedro Caçapaça, Amaro, Acoritene, Osenga, Zumbi, Ganga-Muíça.

Segundo o texto, os indígenas apoiam os quilombos - os oprimidos se unem contra a opressão. Mas a violência dos colonizadores é persistente: "Domingos Jorge Velho decapitou 200 índios que se recusaram a seguir até Palmares para atacar os quilombos" (p.61). Em outra situação, Bartolomeu Bueno retornou a Vila Rica com 3.900 pares de orelhas dos quilombos do Rio das Mortes.

Casa-grande \& senzala é referência central para falar da presença cultural do negro na colônia e no presente: na alimentação, nas palavras - as sílabas moles -, no sincretismo. Na canção de Milton Nascimento e Fernando Brant, O Brasil aprende a ser negro, citada no texto, encontram-se as constatações de Freyre das palavras com sabor africano: Tonin, Tetê, neném, sinhá, papá, mainha... O importante era perceber a presença da África "no trabalho, na cultura, nas lutas pela liberdade, na própria cara do nosso povo moreno, mestiço, preto, cheio de cor".

Enfim, o próprio texto nos dá um resumo da leitura - feita por esse e muitos outros livros dos anos 1980 - a respeito do período de colonização da América portuguesa e - como este é momento fundador - da própria identidade da nação que sobrevive até o presente: "O Brasil nascia, pois, cheio de contrastes. Senhores e escravos. Senhores e homens livres e pobres. Casa-grande e senzala. 'Civilizados' e 'bárbaros'. 'cristãos' e 'infiéis'. Ricos e pobres. Mandões e mandados. Em resumo: dominadores e dominados” (p.32). 


\section{DA INTEGRAÇÃO À INTERVENÇÃO SOCIAL}

Representações ainda em circulação nos anos 1970 buscavam num passado glorioso não só o motivo de orgulho, mas o espelho para a continuidade no presente. Para as obras dos anos 1980, como Brasil Vivo, o passado colonial da sociedade brasileira continua sendo momento fundador, mas pesa negativamente. Sendo função primordial da História atribuir sentido ao presente, era preciso explicar a situação de extrema marginalidade em que vivia a maioria da população brasileira, aí incluídos negros e índios e seus descendentes. Outra versão da história precisava emergir.

Dessa forma, é possível entender como os livros do período analisado tornam-se mais dramáticos, envolventes e emocionais. Fazia-se necessário convencer para despertar para a ação uma população que havia sido alvo de intensa propaganda política desmobilizadora. Assim é que o objetivo da "integração social", mais evidente nos Estudos Sociais, não é mais contemplado e é substituído pela intervenção social, pela necessidade de se questionar a sociedade mediante uma ação coletiva mais consciente. Intencionava-se uma mudança nas representações das identidades e uma transformação estrutural no imaginário, na memória coletiva, e, nessa perspectiva, Brasil Vivo usava de bastante persuasão. Para isso não mobilizava apenas recursos cognitivos (intelectuais), mas também emoções e sentimentos universais relacionados à compaixão para com o sofrimento alheio e à indignação com a injustiça. Nessa leitura, os matizes, as nuanças e a complexidade que envolvem as sociedades eram diminuídas em favor da dicotomia entre opressores e oprimidos.

No entanto, os autores investem em um maior conhecimento da diversidade cultural e étnica brasileira, combatendo a falta de intersubjetividade no processo de formação da identidade histórica e, desta forma, o deficit de reconhecimento, marginalização, na relação moral assimétrica entre similitude e alteridade (cf. Rüsen, 2011, p.148). Há um aprofundamento, não visto em obras didáticas anteriores, no estudo das culturas afro-brasileiras e indígenas.

A sociedade brasileira harmoniosa não existe como representação nas publicações didáticas de História dos anos 1980. No passado e no presente trata-se de uma sociedade permeada por conflitos, violenta e desigual. As 
"desigualdades harmônicas" não figuram mais no horizonte. Essa perspectiva implicou, também, um rompimento com a ideia da "democracia racial".

Os autores de Brasil Vivo, apropriando-se dos intensos debates sobre os rumos do ensino de História, dentro do "clima" da reconquista da democracia, enxergaram um "campo aberto" que possibilitaria ressignificar ou até mesmo refundar as identidades brasileiras na história. Leitores, usuários e produtores deveriam identificar-se, na leitura dos livros, com uma imensa maioria: o povo tradicionalmente explorado. Como a abordagem dos livros tende a ser mais social do que cultural, após a sua leitura seria possível constatar que nós somos um povo fruto da violência e da desigualdade. Continuamos, contudo, sendo um povo, apesar de uma pequena minoria indesejada. Mesmo com todas as contestações, não é a identidade nacional que é posta em xeque, mas sua representação. Houve a "permissão", nesse período, para adotar um tom crítico e iconoclasta com relação a ícones da identidade nacional tradicionalmente construída, mas não para assumir uma visão pessimista com relação às potencialidades do Brasil e dos brasileiros como um povo, representado logo no início de Brasil Vivo, como "a nossa gente", "rica, agitada e viva. Cheia de alegrias e dores".

\section{Disputa PÚBliCA PELOS SENTIDOS DA HistórIA}

Cabe retomar algumas considerações a respeito da relação deste estudo com problemas contemporâneos concernentes ao ensino escolar de História e à intensa disputa pública pelos seus sentidos. Grande parte da reação conservadora, que está mais visível que nunca na atualidade, aproveita-se de algumas fragilidades da maneira de entender a História e sua aprendizagem na escola representada pela maioria das obras didáticas produzidas nos anos $1980,{ }^{7}$ ou seja, de uma história dita "engajada” (com relação à participação popular e às desigualdades sociais) para instaurar um discurso pretensamente relativista, utilizando, em seus textos, excertos de análises acadêmicas. Esse é o caso, por exemplo, dos "guias do politicamente incorreto" 8 que ganharam grande destaque na mídia hegemônica a partir de 2009 com a obra do jornalista Leandro Narloch. ${ }^{9}$ No mesmo caminho está a atuação de um movimento conhecido como "Escola sem Partido". ${ }^{10}$ 
Em que pese o fato de as críticas feitas por esses movimentos serem marcadas pela superficialidade e até mesmo pela desonestidade - em pinçar casos isolados e os contrapor a trechos acadêmicos também recortados dentro de uma suposta neutralidade -, há que se perceber que a compreensão do processo educativo que eles proferem é compartilhada por uma parte significativa da sociedade brasileira. Haja vista a discussão recente provocada pela Base Nacional Comum Curricular (BNCC), em que algumas associações de historiadores manifestaram opiniões alicerçadas em uma concepção de imparcialidade, a partir da qual seria possível a transposição direta de saberes acadêmicos para o ambiente escolar, compreendendo o processo educativo como uma relação que se dá no vácuo.

Toda ação educacional está imersa em complexos contextos socioculturais. Os estudantes, individual e socialmente, não são tábula rasa. Por isso a relação educativa concreta nunca foi apenas de transmissão ou vulgarização de conhecimentos acadêmicos. Competências cognitivas, morais e comportamentais estiveram sempre no horizonte do objetivo de formar novas gerações, papel atribuído à escolarização na sociedade moderna. Diferentemente do conhecimento acadêmico, o saber escolar vai além da transmissão/comunicação de conclusões de pesquisa, para conseguir promover a compreensão, a alteração de esquemas mentais, o questionamento de preconcepções, e instaurar novos habitus.

Portanto, na escolarização como um todo e no ensino de História em especial, desde seus primórdios, os princípios cognitivos estão imbricados com interesses conativos. Os professores de História e os autores de livros didáticos de História - esses professores no texto ${ }^{11}$ - têm que buscar um justo e utópico equilíbrio entre um compromisso maior com o saber acadêmico e a vitalidade que dá significação aos saberes escolares.

$\mathrm{Na}$ interpelação da história acadêmica pela história escolar, produz-se uma axiologização dos saberes. Os frutos da produção acadêmica são inseridos em novas problemáticas - que nem sempre correspondem ao seu contexto de origem - visando atingir questões relativas aos valores culturais e à formação do espírito público. A história escolar, assim produzida, "inclui uma grande quantidade de valores e crenças que se misturam em uma trama de relatos históricos" (Carretero, 2007, p.18). 
Autores de livros didáticos também identificam necessidades sociais, a partir das quais articulam e organizam o passado, dando sentido e atribuindo valor ao novo conhecimento proposto. Os livros didáticos de história dos anos 1980, e em especial Brasil Vivo, percebem claramente que a questão da identidade é central para a aprendizagem da História que se constitui em um diálogo entre memórias diversas, incluindo tradições assentadas em longo prazo. Nesse caso, enfrentam, com as armas disponíveis em seu tempo, o que contemporaneamente identificamos como passados dolorosos ou traumáticos, fazendo emergir outras vozes, outras histórias:

abordar temas sensíveis, como as histórias silenciadas por tanto tempo, implica debater-se com uma memória sedimentada por séculos, mas também com uma série de representações que têm sido criadas sobre o passado dos afrodescendentes, dos indígenas e dos africanos, que se inserem numa aula de História e a tornam esse Caos, complexo, mas criativo, no qual a aprendizagem só é possível se pensado que o que se ensina é muito mais e muito menos que a história acadêmica. (Pereira; Meinerz; Pacievitch, 2015, p.50)

Identificando desigualdades e assimetrias também no mundo das representações, os autores dos livros didáticos analisados empreendem um trabalho de "desfamiliarização" em relação a memórias exaustivamente repetidas, utilizando como antídoto principal novos conhecimentos sobre os embates, conquistas e produções culturais de afro-brasileiros e indígenas, aproximando-se do que, na atualidade, compreendemos como a formação de uma consciência crítica com o objetivo de que os estudantes aprendam "a quebrar as representações práticas eficazes de continuidade e tirar a força da formação da identidade histórica (tradicional) como núcleo central” (Rüsen, 2012, p.82). O enfrentamento de certa esquizofrenia identitária, que impedia a inclusão de outros sujeitos no mundo moderno dos iguais, passava pela afirmação positiva das diferenças num amplo projeto de descolonização.

É nessa direção que se pode lamentar em muitas apreciações e embates contemporâneos, como alguns dos realizados em torno da BNCC, o abandono da discussão da qualidade política dos conteúdos a serem trabalhados na escola. Como se o conhecimento produzido pela academia fosse autoevidente, capaz de tornar-se força criativa, ganhar vitalidade e significação cultural, por um simples passe de mágica, para um amplo e diverso conjunto de crianças, 
adolescentes e jovens no torvelinho da contemporaneidade. É evidente que o passado em si é interpretado pela historiografia e alguma forma de orientação já advém desse processo; no entanto, seu uso pelo presente não é totalmente dado - a orientação é uma das dimensões subjetivas e essenciais do ensino de História que torna a narrativa, que estrutura a relação passado-presente, um tempo pensado.

Se há fragilidades na produção didática dos anos 1980, com a fixidez e o fetichismo de identidades, lógicas binárias e o estabelecimento de dicotomias simplistas entre o bem e o mal, há também perigo quando se transforma o ensino de História em uma espécie de turismo asséptico pelo passado, supostamente neutro e descomprometido. Há muitas possibilidades para superar esse tipo de situação, dentre elas a de tornar o que chamamos de História pública - ou uso público da História - componente da espinha dorsal de uma Licenciatura em História que vise formar professores e pesquisadores para atuar em sociedade. Trata-se da reflexão do profissional pesquisador sobre sua própria prática em termos da função social e suas respectivas consequências políticas: de onde vêm o desejo, a necessidade social e o uso que será feito das conclusões da produção historiográfica. Ficam mais evidente, assim, os propósitos que os dois lugares institucionais - história acadêmica e história escolar - comungam: o desejo de apontar e superar as fragilidades da memória, do senso comum e suprir a carência de orientação no mundo (cf. Rüsen, 2001).

O equilíbrio e a conciliação entre o rigor acadêmico e a vitalidade de um ensino-aprendizagem mais envolvente permanecem como utopia que nos faz caminhar. Os livros produzidos nos anos 1980, quando compreendidos em seu contexto, podem ser bons auxiliares para pensarmos essa vitalidade do conhecimento histórico, o diálogo entre memórias e a atribuição de valor ao passado, proposições com as quais nos defrontamos ainda nesta segunda década do século XXI.

\section{REFERÊNCIAS}

ALENCAR, Chico; RIBEIRO, Marcus V.; CECCOM, Claudius. Brasil Vivo: uma nova história da nossa gente. vol. 1. Petrópolis: Vozes, 1986.

BAUMAN, Zygmunt. Identidade: entrevista a Benedetto Vecchi. Rio de Janeiro: Jorge Zahar, 2005. 
BOURDIEU, Pierre. O poder simbólico. Lisboa: Difel, 1989.

CARRETERO, Mario; ROSA, Alberto; GONZÁLEZ, María Fernanda (Org.) Ensino da História e memória coletiva. Porto Alegre: Artmed, 2007.

FREYRE, Gilberto. Casa-grande \& senzala: formação da família brasileira sob o regime de economia patriarcal. 51.ed. São Paulo: Global, 2007.

GONÇALVES, José Henrique R. Das resistências ao ensino escolar de História da África: algumas considerações. História \& Ensino, Londrina, v.20, n.1, p.83-100, jan./jun. 2014. Disponível em: http://www.uel.br/revistas/uel/index.php/histensino/article/view/14105/14795.

HALL, Stuart. Da Diáspora: identidades e mediações culturais. Belo Horizonte: Ed. UFMG, 2003.

MARTÍN-BARBERO, Jesús. Desafios políticos da diversidade. Revista Observatório Itaú Cultural, São Paulo, OIC, n.8, p.153-159, abr./jul. 2009. Disponível em: http://d3nv1jy4u7zmsc.cloudfront.net/wp-content/uploads/itau_pdf/001516.pdf.

MORENO, Jean Carlos. História na Base Nacional Comum Curricular: déjà vu e novos dilemas no século XXI. História \& Ensino, v.22, p.7-27, 2016. Disponível em: http://www.uel.br/revistas/uel/index.php/histensino/article/view/26158/19188.

. Limites, escolhas e expectativas: horizontes metodológicos para análise dos livros didáticos de História. Antíteses (Londrina), v.5, p.717-740, 2012. Disponível em: http://www.uel.br/revistas/uel/index.php/antiteses/article/view/13317/12648.

. Por textos e contextos: identidade e aprendizagem histórica In:

Entre textos e contextos: caminhos do ensino de História. Curitiba: CRV, 2016. v.1, p.449-470.

Quem somos nós? Apropriações e representações sobre a(s) identidade(s) brasileira(s) em livros didáticos de História (1971-2011). Jundiaí: Paco, 2014.

MUNAKATA, Kazumi. Produzindo livros didáticos e paradidáticos. Tese (Doutorado) - Programa de Estudos Pós-Graduados em Educação: História e Filosofia da Educação, Pontifícia Universidade Católica de São Paulo (PUC-SP). São Paulo, 1997.

PEREIRA, Nilton M.; MEINERZ, Carla B.; PACIEVITCH, Caroline. Viver e pensar a docência em História diante das demandas sociais e identitárias do século XXI. História \& Ensino, Londrina, v.21, n.2, p.31-53, jul./dez. 2015. Disponível em: http://www.uel.br/revistas/uel/index.php/histensino/article/view/23850/17616.

ROSA, Alberto; BELLELLI, Guglielmo; BAKHURST, David. Representaciones del pasado, cultura personal e identidad nacional. Educação e Pesquisa, São Paulo, v.34, n.1, p.167-195, jan./abr. 2008. Disponível em: http://www.revistas.usp.br/ep/article/view/28083/29890. 
RÜSEN, Jörn. Aprendizagem histórica: fundamentos e paradigmas. Curitiba: W. A. Editores, 2012. . Humanismo e didática da História. Curitiba: W. A. Ed., 2015. . Razão Histórica. Teoria da história I: os fundamentos da ciência histórica. Brasília: Ed. UnB, 2001. .; SCHMIDT, Maria A.; BARCA, Isabel; MARTINS, Estevão de R. (Org.) Jörn Rüsen e o ensino de História. Curitiba: Ed. UFPR, 2011.

WOODWARD, Kathryn. Identidade e diferença: uma introdução teórica e conceitual. In: SILVA, Tomaz Tadeu (Org.) Identidade e Diferença: a perspectiva dos estudos culturais. 9.ed. Petrópolis, RJ: Vozes, 2009.

\section{NOTAS}

${ }^{1}$ Uma parte modificada deste texto foi publicada nos anais do XV Encontro Regional de História (2016) com o título "Senhores e escravos. Ricos e pobres. Mandões e mandados. Brasil Vivo: um marco na produção didática de História da década de 1980".

${ }^{2}$ Estes últimos menos racializados, desempenhando vários papéis sociais como navegadores/exploradores portugueses, senhores de engenho, bandeirantes ou jesuítas.

${ }^{3}$ Segundo depoimento de Rubim Aquino, os autores de História da Sociedade Brasileira e História das Sociedades (marcos importantes da produção didática de História no Brasil), formavam, inicialmente, um mesmo grupo - nos finais dos anos 1970 -, desmembrado para a melhor execução dos dois projetos.

${ }^{4}$ Foi, por exemplo, um dos cinco fundadores do jornal O Pasquim.

${ }^{5}$ Essa perspectiva já estava incipiente no discurso do índio tupinambá de Montaigne, citado em obras da década de 1970.

${ }^{6} \mathrm{~A}$ opção pela importação de mão de obra africana é abordada anteriormente, na página 31: "os índios do Brasil não estavam habituados a horas seguidas de trabalho agrícola. Por isso, deixaram logo de ser utilizados pelos senhores de engenho, que passaram a considerá-los 'incapazes e preguiçosos"'. A maioria dos livros didáticos do período, no entanto, ressaltaria o lucro do tráfico como causa principal da opção pela escravidão africana.

${ }^{7}$ Que podem ser entendidas como um modelo cujo último representante foi a obra História Crítica, de Mário Schmidt (2005).

${ }^{8}$ Os "Guias do Politicamente Incorreto" não são uma invenção brasileira. Fazem parte de um conjunto de ações, ou melhor, de reações de parte da tradição conservadora norte-americana aos embates linguísticos e culturais trazidos pela afirmação do "politicamente correto". Entre seus alvos principais, explicitados ou não, estariam as conquistas das chamadas minorias que se processam desde os finais dos anos 1960, como, por exemplo, os 
direitos civis, as políticas de reparações à escravidão, o feminismo, o discurso ecológico-ambiental etc. Assim, tem-se The Politically Incorrect Guide to American History; The Politically Incorrect Guide to Islam; The Politically Incorrect Guide to Women, Sex, and Feminism; The Politically Incorrect Guide to Hunting; The Politically Incorrect Guide to The Sixties; The Politically Incorrect Guide to the Vietnam War.

${ }^{9}$ Uma análise pouco mais detalhada pode ser encontrada em MORENO, 2014.

${ }^{10}$ O "Escola sem Partido" apresenta, desde 2014, projetos de Lei de restrição à atuação docente. Na impossibilidade de uma análise mais profunda, cabe ressaltar que essas e outras estratégias, que flertam com o fascismo, têm origem na reação conservadora norte-americana iniciada nos anos 1990 e depois estruturada em um amplo movimento que ficou conhecido como Tea Party. Basicamente esse modelo que se espalha especialmente pela América Latina define a realidade contemporânea como uma guerra ideológica contra os direitos das minorias, o multiculturalismo, o Estado laico, o humanismo crítico, o ambientalismo, o feminismo e o Estado de Bem-Estar Social.

${ }^{11}$ A expressão é de uma entrevista realizada para a confecção da tese de MUNAKATA (1997).

Artigo recebido em 13 de janeiro de 2017. Aprovado em 20 de fevereiro de 2017. 